\title{
On the electro-oxidation of small organic molecules: towards a fuel cell catalyst testing platform based on gas diffusion electrode setups
}

Damin Zhang ${ }^{\mathrm{a}}$, Jia Du ${ }^{\mathrm{a}}$, Jonathan Quinson ${ }^{\mathrm{b}}$, Matthias Arenz ${ }^{\mathrm{a}}$

a Department of Chemistry, Biochemistry and Pharmaceutical Sciences, University of Bern, Freiestrasse 3, 3012 Bern, Switzerland

b Department of Chemistry, University of Copenhagen, Universitetsparken 5, 2100 Copenhagen $\emptyset$, Denmark

* Corresponding author: matthias.arenz@unibe.ch

\begin{abstract}
The electrocatalytic oxidation of small organic compounds such as methanol or formic acid has been the subject of numerous investigations in the last decades. The motivation for these studies is often their use as fuel in so-called direct methanol or direct formic acid fuel cells, promising alternatives to hydrogen-fueled proton exchange membrane fuel cells. The fundamental research spans from screening studies to identify the best performing catalyst materials to detailed mechanistic investigations of the reaction pathway. These investigations are commonly performed at conditions quite different to fuel cell devices, where no liquid electrolyte will be present. We previously developed a gas diffusion electrode setup to mimic "real-life" reaction conditions and study electrocatalysts for oxygen gas reduction or water splitting. It is here demonstrated that the setup is also suitable to investigate the properties of catalysts for the electro-oxidation of small organic molecules simulating conditions of low temperature proton exchange membrane fuel cells.
\end{abstract}

\section{Keywords}


Methanol oxidation; formic acid oxidation; direct methanol fuel cell; direct formic acid fuel cell; gas diffusion electrode setup;

\section{Introduction}

Energy conversion and storage are the most prominent applications of electrochemistry. Electrochemical energy conversion is required to use electric energy for producing fuels and chemicals, e.g., in water electrolysis or carbon dioxide electroreduction, but also to transform fuels to electric energy. The most common fuel thereby is gaseous hydrogen, which can be converted into electric energy using proton exchange fuel cells (PEMFCs). Hydrogen powered PEMFCs are for example used in automotive applications where an extremely high-power density is required [1]. The main challenges for the technology however are the lack of a hydrogen distribution system and the high costs [2]. Liquid fuels such as methanol or formic acid by comparison are easier to distribute and store. However, operating PEMFCs with liquid fuels in so-called direct liquid fuel cells, i.e., direct methanol and direct formic acid fuel cells (DMFC and DFAFCs) [3], requires substantially larger amounts of the precious and rare catalyst materials to reach a given $\mathrm{kW}$ peak power demand due to the sluggish anode reaction [4] in addition to the limited cathode performance. The sluggish anode reaction is mostly associated with the a limited complete oxidation of the fuel to $\mathrm{CO}_{2}[5,6]$. For example, methanol oxidation reaction is known to proceed via a $\mathrm{CO}$ intermediate which adsorbs to the catalyst surface and thus blocks (poisons) adsorption sites [7]. As a consequence, the $\mathrm{CO}$ oxidation reaction becomes the limiting factor for methanol oxidation. By comparison, formic acid should facilitate the direct oxidation to $\mathrm{CO}_{2}$ via the removal of two the hydrogen atoms. Nevertheless, also for formic acid oxidation, CO poisoning has been reported [8,9]. Despite these limitations, direct liquid fuel cells are an interesting alternative for applications where lower power densities are required. 
The first steps in catalyst development for PEMFCs are usually performed in rotating disk electrode (RDE) measurements in three-compartment electrochemical cells with liquid electrolyte [10]. Such experiments are straightforward to set up, but for cathode catalysts promoting the oxygen reduction reaction (ORR), it has been observed that the extrapolation of the results to real applications or even measurements in single cell membrane electrode assemblies (MEA) is challenging [11]. This is mostly due to different mass transport conditions, but the electrolyte environment in PEMFCs is also considerably different than in RDE measurements. For this reason, several research groups developed experimental approaches for catalyst testing that aim to establish a second testing platform bridging RDE and MEAs [12-24], one of these platforms is the gas diffusion electrode (GDE) setup. As pointed out, the main motivation in developing GDE setups is to establish high reactant mass transport which is crucial for gaseous reactants such as oxygen [18]. However, also the electrolyte type, i.e., liquid or membrane, is expected to have a significant influence on the catalyst reactivity. It is well known for example that the determined ORR activity of Pt based catalysts is substantially different in sulfuric and in perchloric acid based aqueous electrolytes [6]. This phenomenon is related to structure sensitive, specific anion adsorption blocking active catalyst sites and the term spectator species was introduced for anions in the liquid electrolyte as they have no active part in the ORR. Nafion, by comparison, which is often used as membrane electrolyte, does not exhibit structure specific adsorption, although it blocks active catalyst sites as well $[25,26]$.

Although it has been shown that even non-specifically absorbed cations can influence catalytic reactions [27], to the best of our knowledge so far it has not been investigated to which degree the electrolyte environment, i.e., aqueous or membrane electrolyte, influences the oxidation of small organic molecules, e.g., methanol and formic acid. In the present study, we therefore compare the performance of two standard catalysts for the methanol and formic acid oxidation, 
i.e., Pt and $\mathrm{Pd}$ nanoparticles supported on high surface area carbon $(\mathrm{Pt} / \mathrm{C}$ and $\mathrm{Pd} / \mathrm{C})$ and performed investigations in a conventional electrochemical (RDE) setup as well as in a GDE setup. We thereby simulate the conditions in a low temperature proton exchange fuel cell (LTPEMFC), i.e., a Nafion/catalyst interface.

\section{Experimental Methods}

\section{Materials and chemicals}

The following materials and chemicals were used: Commercial Pt/C (Tanaka Kikinzoku Group, TEC10E20A, 19.4\%) and Pd/C (FC Catalyst, 3151611, 20\% Palladium on Vulcan), $37 \%$ hydrochloric acid ( $\mathrm{HCl}$, Suprapur, Merck), $65 \%$ nitric acid $\left(\mathrm{HNO}_{3}\right.$, Suprapur, Merck), methanol $\left(\mathrm{CH}_{3} \mathrm{OH}\right.$, VWR Chemicals, 98.5\%), formic acid (HCOOH, $\geq 95 \%$, Sigma Aldrich), isopropanol (IPA, 99.7+\%, Alfa Aesar), 70\% perchloric acid $\left(\mathrm{HClO}_{4}\right.$, ACS reagent, $70 \%$, Sigma-Aldrich), KOH (pellets for analysis EMSURE®,Merck), Nafion ${ }^{\mathrm{TM}}$ D1021 Dispersion (Water based $1100 \mathrm{EW}$ at $10 \mathrm{wt} \%$ ), Ultrapure water (resistivity>18.2 $\mathrm{M} \Omega \cdot \mathrm{cm}$, total organic carbon (TOC) < $5 \mathrm{ppb}$ ) from a Milli-Q system (Millipore). The following gases from Carbagas AG were used for electrochemical measurements: Ar (99.999\%), and CO (99.97\%). Gas Diffusion Layer (GDL) without a Microporous Layer (MPL) (Freudenberg H23), Gas Diffusion Layer (GDL) with a Microporous Layer (MPL) (Freudenberg H23C8) and Nafion membrane (Nafion 117, Fuel Cell Store) or anion exchange membrane (Sustainion ${ }^{\circledR}$ X37-50 Grade RT, Fuel Cell Store) were used for the catalyst layer fabrication.

\section{Electrochemical measurements}

All electrochemical measurements were performed in a three-electrode system controlled by a potentiostat (ECi 200, Nordic Electrochemistry). If not specifically noted, the same electrochemical procedures (catalyst loadings, treatment, electrolyte, measurement protocol, 
etc.) were applied for the $\mathrm{Pt} / \mathrm{C}$ and $\mathrm{Pd} / \mathrm{C}$ catalyst. All measurements have been conducted at room temperature.

\section{Measurements in conventional electrochemical cell}

A glassy carbon electrode ( $5 \mathrm{~mm}$ diameter) was used as the working electrode, a platinum wire was used as counter electrode and a reversible hydrogen electrode (RHE) as reference electrode. The electrolyte was either $1.0 \mathrm{M} \mathrm{HClO}_{4}$ or $1.0 \mathrm{M} \mathrm{KOH}$ aqueous solution. The effective solution resistance was determined online with the help of a superposed AC signal $(5 \mathrm{mV}, 5 \mathrm{kHz})$ and was compensated to a value below $5 \Omega$ via an analogue positive feedback scheme of the potentiostat [28].

The catalyst ink for the RDE measurements was prepared by ultrasonically dispersing (ultrasound cleaning bath VWR, USC-THD, $45 \mathrm{kHz}$ ) [10] the catalyst powder (amount corresponding to $0.276 \mathrm{mg}$ metal, e.g., $1.380 \mathrm{mg}$ of $20 \mathrm{wt}$ \% Pd/C ) for ca. $8 \mathrm{~min}$ in $1.266 \mathrm{~mL}$ of a mixed solution containing isopropanol and water $(1: 3 ; \mathrm{v}: \mathrm{v})$ and $11.04 \mu \mathrm{L}$ of $10 \mathrm{wt} \%$ Nafion solution to form a homogeneous catalyst ink with a metal concentration of $0.218 \mathrm{mg}_{\mathrm{metal}} \mathrm{mL}^{-1}$. The RDE working electrodes were fabricated by pipetting $9.0 \mu \mathrm{L}$ of the electrocatalyst ink onto a glassy carbon electrode leading a nominal metal loading of $10 \mu \mathrm{g}_{\text {metal }} \mathrm{cm}^{-2}$ geo, followed by drying in air.

The electrolyte was deaerated by purging with Ar. Prior to the measurements the catalysts were cleaned by potential cycling between $0.15 \mathrm{~V}_{\mathrm{RHE}}$ and $1.20 \mathrm{~V}_{\mathrm{RHE}}$ at a scan rate of $500 \mathrm{mV} \mathrm{s}^{-1}$ until a stable cyclic voltammogram (CV) could be observed. The electrochemically active surface area (ECSA) was determined via the CO oxidation charge in CO monolayer stripping experiments [29]. For this, the electrode was held at $0.15 \mathrm{~V}_{\mathrm{RHE}}$ in a CO-saturated electrolyte for $2 \mathrm{~min}$. Thereafter the electrolyte was saturated for $10 \mathrm{~min}$ with Ar gas to replace the excess $\mathrm{CO}$ in the electrolyte. Finally, the adsorbed $\mathrm{CO}$ monolayer was oxidized to $\mathrm{CO}_{2}$ by scanning 
the electrode potential from 0.15 to $1.10 \mathrm{~V}_{\mathrm{RHE}}$ or $1.20 \mathrm{~V}_{\mathrm{RHE}}$ at a scan rate of $50 \mathrm{mV} \mathrm{s}^{-1}$. The ECSA was estimated from the recorded oxidation charge by using a reference oxidation charge value for polycrystalline Pt of $420 \mu \mathrm{C} \mathrm{cm}^{-2} \mathrm{Pt}$ [30] and Pd of $405 \mu \mathrm{C} \mathrm{cm}^{-2} \mathrm{Pd}$ [31], respectively. The cyclic voltammetry measurements were recorded in the same potential window and at the same scan rate of $50 \mathrm{mV} \mathrm{s}^{-1}$, but in Ar-saturated electrolyte solution. The electrochemical oxidation of formic acid and methanol, respectively, was performed by collecting cyclic voltammetry curves in a Ar-saturated electrolyte solution containing $1.0 \mathrm{M} \mathrm{HClO}_{4}$ and $0.5 \mathrm{M}$ $\mathrm{HCOOH}, 1.0 \mathrm{M} \mathrm{HClO}_{4}$ and $0.5 \mathrm{M} \mathrm{CH}_{3} \mathrm{OH}$, or $1.0 \mathrm{M} \mathrm{KOH}$ and $0.5 \mathrm{M} \mathrm{CH}_{3} \mathrm{OH}$ at a scan rate of $50 \mathrm{mV} \mathrm{s}^{-1}$ in a potential window between 0.15 and $1.20 \mathrm{~V}_{\mathrm{RHE}}$ (formic acid oxidation) or between 0.2 and $1.10 \mathrm{~V}_{\mathrm{RHE}}$ (methanol oxidation). Due to the high reactant concentration, no rotation was applied. Indeed rotation leads to a reduction in the observed reaction rates, see Figure S1.

\section{Electrochemical measurements in gas diffusion electrode setup}

In the gas diffusion electrode setup, instead of the GC electrode, a GDE (3 mm diameter) was used as the working electrode (WE), a platinum wire as counter electrode (CE) and a reversible hydrogen electrode (RHE) as reference electrode (RE). The WE is separated from the CE and RE by a Nafion membrane [32] or an anion exchange membrane (for $\mathrm{KOH}$ solution) in the upper cell compartment above the membrane $1.0 \mathrm{M} \mathrm{HClO}_{4}$ or $1.0 \mathrm{M} \mathrm{KOH}$ aqueous solution was used as electrolyte. All gases purged through the GDE were humidified by first passing through MilliQ water or the reactant solution. It has been previously shown that at room temperature full humidification is reached [32].

WE preparation: The catalyst (amount corresponding to $0.382 \mathrm{mg}$ metal) was ultrasonically (ultrasound cleaning bath VWR, USC-THD, $45 \mathrm{kHz}$ ) dispersed for ca. $8 \mathrm{~min}$ in $7.645 \mathrm{~mL}$ of a mixed solution containing isopropanol, water (3:1; v:v) and $15.29 \mu \mathrm{L}$ of $10 \mathrm{wt} \%$ Nafion (10:1; $\left.\mathrm{ul}: \mathrm{mg}_{\text {Carbon }}\right)$ solution to form a homogeneous $0.05 \mathrm{mg}_{\text {metal }} \mathrm{mL}^{-1}$ catalyst ink. The catalyst was 
deposited on the GDL with a MPL by vacuum filtration leading to a nominal loading of 200 $\mu \mathrm{g}_{\text {metal }} \mathrm{cm}^{-2}$ geo [33]. A blank GDL with MPL with a diameter of $2 \mathrm{~cm}$ was taken and a $3 \mathrm{~mm}$ hole was punched out in its centre. This was placed onto a GDL without MPL and in the hole a $3 \mathrm{~mm}$ catalyst coated GDL was placed and everything was pressed, protected by a Teflon sheet, to a Nafion membrane of $1 \mathrm{~cm}$ in diameter by a hydraulic press $(2$ tons pressure, $5 \mathrm{~min}$, room temperature) [21]. For the anion exchange membrane a reduced pressure was applied (1 ton pressure, $5 \mathrm{~min}$, room temperature) to avoid sticking to the Teflon sheet.

The system was deaerated by purging the GDE through the bottom cell part with humidified Ar [32]. Prior to the measurements the catalysts were cleaned by potential cycling between $0.15 \mathrm{~V}_{\mathrm{RHE}}$ and $1.20 \mathrm{~V}_{\mathrm{RHE}}$ at a scan rate of $500 \mathrm{mV} \mathrm{s}^{-1}$ until a stable $\mathrm{CV}$ could be observed, The CO stripping measurements were performed as in the conventional cell, i.e., the electrode was held at $0.15 \mathrm{~V}_{\mathrm{RHE}}$ with streaming $\mathrm{CO}$ through the cell for $2 \mathrm{~min}$, thereafter the $\mathrm{CO}$ was replaced by $\mathrm{Ar}$ gas to remove all excess $\mathrm{CO}$. The adsorbed $\mathrm{CO}$ monolayer was oxidized to $\mathrm{CO}_{2}$ by scanning the electrode potential from 0.15 to $1.20 \mathrm{~V}_{\mathrm{RHE}}(\mathrm{Pd})$ or $1.10 \mathrm{~V}_{\mathrm{RHE}}(\mathrm{Pt})$ at a scan rate of $50 \mathrm{mV} \mathrm{s}^{-1}$. The ECSA was estimated from the recorded oxidation charge using the same reference values as in the RDE measurements.

The electrochemical oxidation of formic acid and methanol, respectively, was performed by passing Ar through reactant mixed in aqueous solution instead of pure MilliQ water. Different concentrations of reactants mixed in aqueous solution were tested to exclude reactant mass transport limitations, see Figure S2, and we decided to use the highest tested concentrations of 5.0 $\mathrm{M} \mathrm{HCOOH}$ or 5.0 $\mathrm{M} \mathrm{CH}_{3} \mathrm{OH}$ where already an inhibiting effect similar to the rotation effect in the RDE was observed to ensure no mass transport limitations. The cyclic voltammetry curves were collected at a scan rate of $50 \mathrm{mV} \mathrm{s}^{-1}$ in the same potential range as noted above.

\section{Physical characterization of the catalysts}


The size (diameter) and shape of the Pt and Pd nanocatalysts were evaluated by TEM using a Jeol 2100 transmission electron microscope operated at $200 \mathrm{kV}$. For the characterization, at least three images in at least three different randomly selected areas of the grids were chosen. The samples were prepared by dropping the catalyst ink (the catalyst was diluted in ethanol) onto carbon coated copper TEM grids. The nanoparticle size was evaluated by measuring the diameter of at least 200 nanoparticles using the software ImageJ.

In order to evaluate the nanoparticle size with more statistical power (given that TEM analysis is limited to few hundreds of individual nanoparticles), small angle X-ray scattering were performed as previously described in detail [21]. The $\mathrm{Pd} / \mathrm{C}$ or $\mathrm{Pd} / \mathrm{C}$ powders were placed in dedicated holders in between two mica windows. The measurements performed at the Niels Bohr Institute at the University of Copenhagen using a SAXSLab instrument. The data were fitted with polydisperse spheres models described by a volume-weighted log-normal distribution.

\section{Inductively Coupled Plasma Mass Spectrometry (ICP-MS)}

The actual metal loadings of WE were evaluated by ICP-MS (NexION 2000 ICP-MS). The ICP-MS was equipped with a cyclonic spray chamber and a PFA-nebulizer. The RF power for the plasma was held at $1300 \mathrm{~W}$ with a gas flow of $15 \mathrm{~L} \mathrm{~min}^{-1}$. The catalysts on the GDLs were selected 4 different parts and dissolved in aqua regia (volume ratio of $\mathrm{HCl}: \mathrm{HNO}_{3}=3: 1$ ) and then diluted to $200 \mathrm{~mL}$ with milli-Q water. Based on four different measurements average metal loadings of $141 \mu \mathrm{g}_{\mathrm{Pd}} \mathrm{cm}^{-2}$ geo and $143 \mu \mathrm{g}_{\mathrm{Pt}} \mathrm{cm}^{-2}$ geo for $\mathrm{Pd} / \mathrm{C}$ and $\mathrm{Pt} / \mathrm{C}$, respectively, were determined. To evaluate the real catalyst loading on the RDE tips, $9 \mu$ of the catalyst ink was taken and dissolved in $4 \mathrm{~mL}$ aqua regia (volume ratio of $\mathrm{HCl}: \mathrm{HNO}_{3}=3: 1$ ) and then diluted to $25 \mathrm{~mL}$ with milli-Q water. By ICP-MS, metal loadings of $8.0 \mu \mathrm{g}_{\mathrm{Pd}} \mathrm{cm}^{-2}$ geo and $7.5 \mu \mathrm{g}_{\mathrm{Pt}} \mathrm{cm}^{-2}$ geo on the RDE tips were estimated. 


\section{Results and Discussion}

As discussed in the introduction, the aim of this work is to establish the suitability of the GDE approach for volatile organic reactants simulating a LT-PEMFC environment. For this purpose, we investigate the performance of two standard catalysts, i.e., $\mathrm{Pt} / \mathrm{C}$ and $\mathrm{Pd} / \mathrm{C}$, for the methanol and formic acid oxidation in a GDE setup with a catalyst - membrane electrolyte interface where the reactant is introduced via a humidified gas stream. The experimental setup for the GDE measurements is relatively new and has been previously only used for studying the electro-oxidation of volatile small organic molecules at rather demanding conditions, i.e., hot phosphoric acid simulating conditions in high-temperature PEMFCs [34]. The setup adopted for simulating LT-PEMFC conditions is schematically displayed in Figure 1. Most importantly, in this configuration the catalyst has only contact to the reactant in water and the membrane electrolyte, but no solvated anions such as e.g., perchlorate anions. As benchmark, we compared the GDE measurements to investigations conducted in a conventional electrochemical cell (RDE setup) with aqueous supporting electrolyte to which the reactant, i.e., methanol or formic acid is added. 


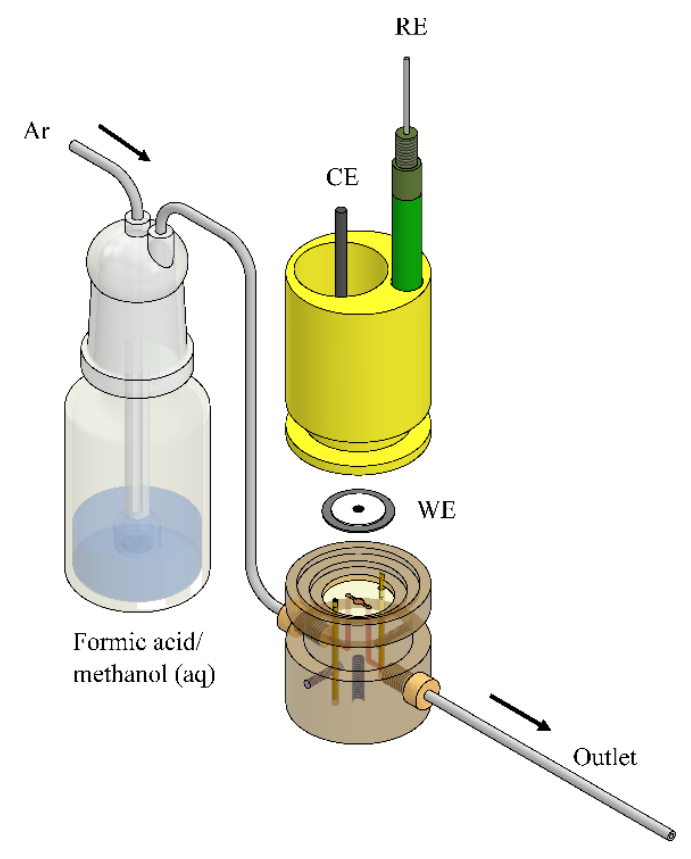

Figure 1. Sketch of the experimental setup for the GDE measurements. The formic acid or methanol is brought to the catalyst layer (WE) on the GDL via a humidified Ar gas stream. CE and RE indicate counter and reference electrode and are separated from the WE by a membrane electrolyte, i.e. proton or anion exchange membrane (not shown).

Before we discuss the results of the electrochemical measurements, we introduce the physical characterization by TEM and SAXS of the investigated commercial catalysts. TEM micrographs as well as the particle size distributions determined by TEM and SAXS are shown in Figure 2, the fits of the SAXS data are shown in Figure S3 in the supporting information. Both, the commercial $\mathrm{Pt} / \mathrm{C}$ and the $\mathrm{Pd} / \mathrm{C}$ exhibit homogeneously distributed nanoparticles on the carbon support and a well-defined particle size. Consistent results are obtained comparing the results of the local method TEM with the results of the "integrating" (i.e., probing a macroscopic part of the catalyst) method SAXS. The histogram of the particle size evaluated by TEM and the probability function determined by SAXS reveal an average size of $1.6 \pm 0.4$ $\mathrm{nm}$ and $1.8 \pm 0.2 \mathrm{~nm}$, respectively, for the $\mathrm{Pt} / \mathrm{C}$ catalyst. By comparison, the Pd particle size is slightly larger with an average size of $4.2 \pm 0.9 \mathrm{~nm}$ and $4.8 \pm 0.3 \mathrm{~nm}$, determined by TEM and SAXS, respectively. 

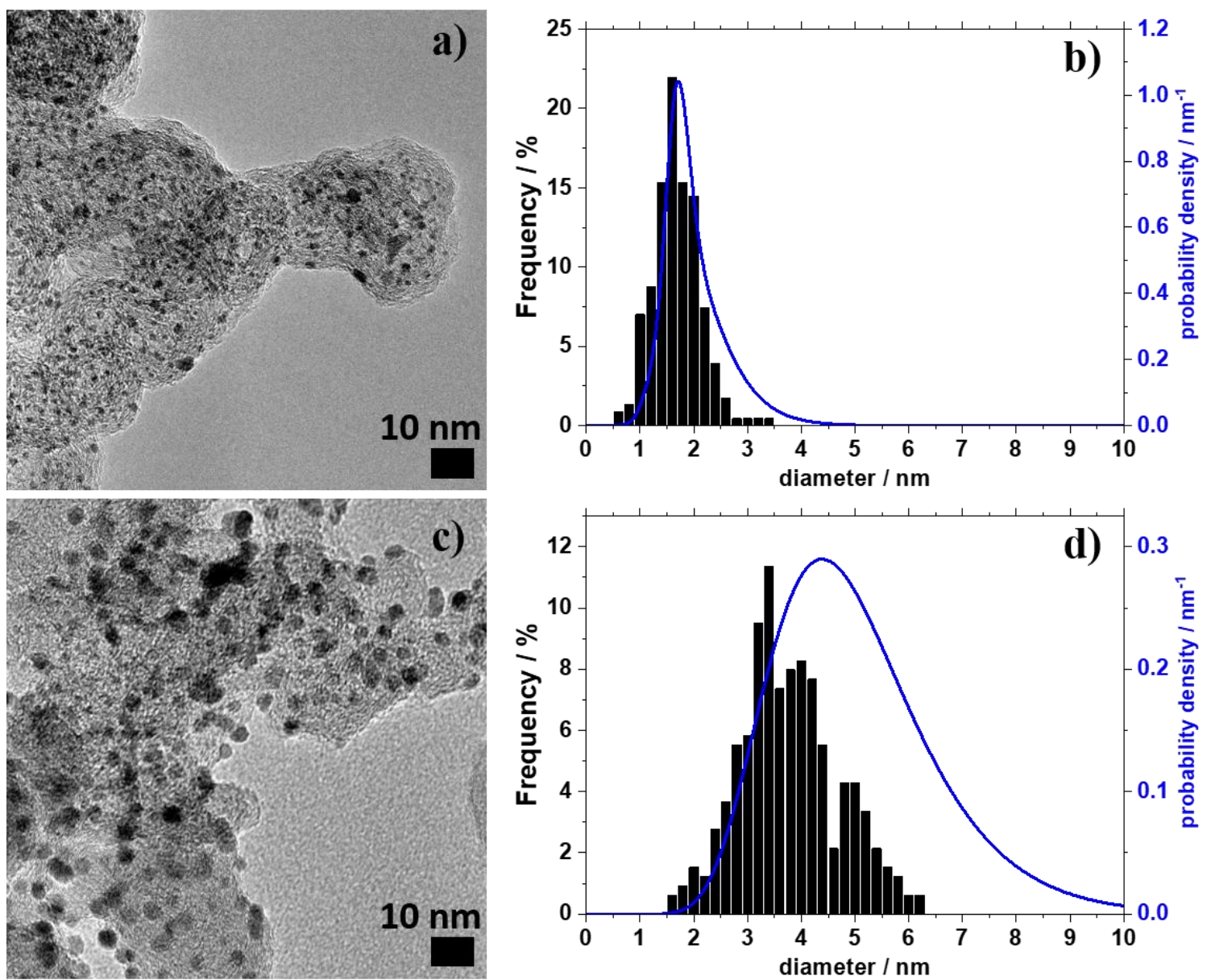

Figure 2. Representative TEM micrographs of the commercial a) Pt/C and c) Pd/C catalyst. Particle size distributions derived from TEM (black size histogram) and SAXS (blue probability density function) of b) $\mathrm{Pt} / \mathrm{C}$ and d) $\mathrm{Pd} / \mathrm{C}$. For the particle size histograms 228 nanoparticles for Pt and 330 nanoparticles for $P d$ were analyzed.

Investigating the catalytic performance of fuel cell catalysts, one typically starts with recording $\mathrm{CVs}$ in inert atmosphere followed by a determination of the electrochemically active surface area (ECSA). The respective measurements for $\mathrm{Pt} / \mathrm{C}$ and $\mathrm{Pd} / \mathrm{C}$ are summarized in Figure 3. In the discussion we concentrate on the similarities and differences of the electrochemical behavior of the respective catalysts in the RDE and GDE setup. Independent of the electrochemical setup and the catalyst, all CVs confirm a "standard response" to the cycling of the electrode potential in inert atmosphere and a "clean" catalyst surface. Despite the different catalyst loadings and the resulting different current densities in the RDE and GDE setup, for both, $\mathrm{Pt} / \mathrm{C}$ and $\mathrm{Pd} / \mathrm{C}$ the electrochemical response in the two cell types is comparable. The 
typical responses of hydrogen under potential deposition $\left(\mathrm{H}_{\text {upd }}\right)$ at low electrode potentials $\left(0.15-0.30 \mathrm{~V}_{\mathrm{RHE}}\right)$ and electrochemical oxide formation at higher potentials $\left(0.70-0.90 \mathrm{~V}_{\mathrm{RHE}}\right)$ are clearly discernible and well separated by a potential region double layer formation (ca. 0.30 $\left.-0.60 \mathrm{~V}_{\mathrm{RHE}}\right)$ on $\mathrm{Pt}$ and $\mathrm{Pd}[35,36]$. Furthermore, a clear hysteresis, i.e., a shift in peak potential between positive and negative going scan, is seen in the potential region of oxide formation and reduction ( $>0.60 \mathrm{~V}_{\mathrm{RHE}}$ ) [37]. The hysteresis indicates that oxide formation and reduction are rather slow and irreversible processes. This is of importance for the later discussion as surface oxides de-activate the surface by blocking adsorption sides.
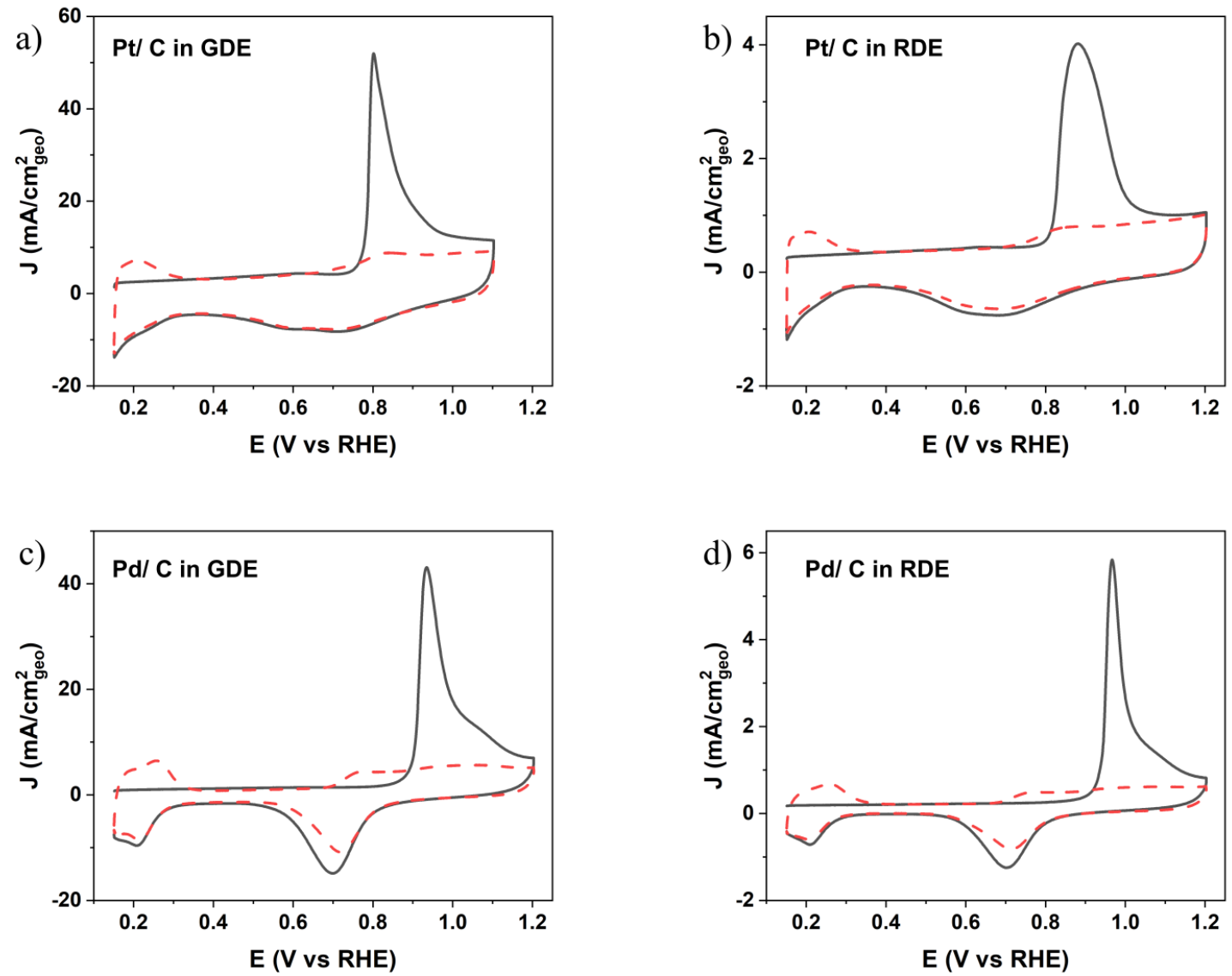

Figure 3. CVs (red dashed lines) and CO stripping voltammograms (black lines) recorded in GDE setup a) $\mathrm{Pt} / \mathrm{C}$, c) $\mathrm{Pd} / \mathrm{C}$ and in $\mathrm{RDE}$ setup b) $\mathrm{Pt} / \mathrm{C}, \mathrm{d}$ ) $\mathrm{Pd} / \mathrm{C}$. The CVs and CO stripping voltammograms were recorded with a scan rate of $50 \mathrm{mV} \mathrm{s} \mathrm{s}^{-1}$ in Ar saturated $1.0 \mathrm{M} \mathrm{HClO}_{4}$ electrolyte (RDE) and under humidified Ar atmosphere (GDE), respectively. All measurements were recorded at room temperature. 
Also the CO stripping voltammograms for $\mathrm{Pt} / \mathrm{C}$ and $\mathrm{Pd} / \mathrm{C}$ in both cell types are similar, but the peak potential and peak width are slightly different. For both catalysts, in the GDE setup the peak potentials of the CO stripping peaks are slightly shifted to lower potentials as compared to the RDE measurements. As the film thickness in the GDE does not influence the position of the CO stripping peak, see Figure $\mathrm{S} 4$, these differences are proposed to be the result of a different electrolyte environment, i.e., aqueous electrolyte with mobile perchlorate anions as compared to a membrane electrolyte, influencing the $\mathrm{CO}$ stripping voltammograms. That is, the interaction with perchlorate anions slightly shifts the $\mathrm{CO}$ oxidation to higher potentials.

The ECSA determination based on the $\mathrm{CO}$ stripping measurements is required when distinguishing between mass and surface area normalized (specific) currents. Furthermore, it can be used to confirm a full utilization of the catalyst layer in the GDE setup. In RDE measurements typically a full utilization of the catalyst layer is achieved due to the very thin catalyst film (nominal catalyst loading of $10 \mu \mathrm{g}_{\text {metal }} \mathrm{cm}^{-2}$ geo on the GC electrode). On the other hand, the investigation of realistic film thicknesses is not feasible due to a loss in accessibility of active sites, i.e., a decrease in ECSA with increasing film thickness [38]. By comparison, in the GDE a roughly twenty times thicker catalyst layer is applied without loss in ECSA, see Figure S4. This means that in contrast do RDE measurements [38], in GDE measurements the ECSA does not depend on the catalyst loading and measurements under more relevant reaction conditions to what is actually used in fuel cell devices are feasible. As the GDE contains no liquid electrolyte in direct contact to the catalyst layer, a proper contact of the nanoparticles with the membrane electrolyte in the catalyst layer is required. This is achieved in the GDE setup by a simple pressing procedure [21].

Integrating the $\mathrm{CO}$ stripping voltammograms recorded in the conventional RDE setup leads to ECSA values of $\sim 153 \mathrm{~m}^{2} \mathrm{~g}^{-1} \mathrm{Pt}$ and $\sim 130 \mathrm{~m}^{2} \mathrm{~g}^{-1} \mathrm{Pd}$. A correction via the actual metal concentration in the inks by ICP-MS led to even slightly higher values of $\sim 181 \mathrm{~m}^{2} \mathrm{~g}^{-1} \mathrm{Pt}$ and $149 \mathrm{~m}^{2} \mathrm{~g}^{-1} \mathrm{Pd}$ for 
$\mathrm{Pt} / \mathrm{C}$ and $\mathrm{Pd} / \mathrm{C}$, respectively. The different ECSAs for $\mathrm{Pt} / \mathrm{C}$ and $\mathrm{Pd} / \mathrm{C}$ can be roughly compared with the different average particle size of the two catalysts. Assuming the nanoparticles are perfect spheres and no interface between the metal surface and the carbon support, ECSAs of the "free standing particles" of $165 \mathrm{~m}^{2} \mathrm{~g}^{-1} \mathrm{Pt}$ and $119 \mathrm{~m}^{2} \mathrm{~g}^{-1} \mathrm{Pd}$ for $\mathrm{Pt} / \mathrm{C}$ and $\mathrm{Pd} / \mathrm{C}$, respectively, are calculated using the average particle size determined from TEM. Typically the surface area of "the free standing particles" is higher than the ECSA measured for "the supported particles" and the difference is assigned to the metal - support interface inaccessible for $\mathrm{CO}$ adsorption. In the present work, the correction of the ECSA values by the metal concentration measured in ICP-MS leads to higher ECSA values of "the supported particles". While the comparison is only a rough calculation, this finding might indicate that both catalysts contain many particles which are smaller than the average size determined by TEM.

By comparison the ECSA determination in the GDE setup (corrected by the catalyst loading determined by ICP-MS) led to values of $124 \mathrm{~m}^{2} \mathrm{~g}^{-1} \mathrm{Pt}$ and $123 \mathrm{~m}^{2} \mathrm{~g}^{-1} \mathrm{Pd}$ for Pt/C and $\mathrm{Pd} / \mathrm{C}$, respectively. That is, the ECSA measured in the GDE setup tends to be slightly lower than in the RDE setup. This phenomenon might be related to the explained by the presence of Nafion in the GDE layer. Nafion is known to partially block the active surface area of the active catalyst phase and thus reduces the ECSA [25]. Although, we used also Nafion in the conventional cell with liquid electrolyte, the situation is different as the Nafion serves more as a binder to the glassy carbon tip. Due to the liquid electrolyte, no Nafion is required to "electrically contact" the active phase of the catalyst. As a consequence, in the following we normalized the reaction rates to the number of electrochemically active sites determined by $\mathrm{CO}$ stripping, i.e., we analyse and compare the specific activities in both setups.

After having characterized the catalysts in the supporting electrolyte (aqueous and membrane electrolyte) and having determined the number of electrochemically active sites, we studied the methanol and formic acid electro-oxidation reactions. In the activity measurements, it has been 
noticed that in the GDE setup for catalyst loadings in the range of what is used in RDE measurements substantially higher activities as compared to RDE measurements, see Figure S5, are obtained. However, it was seen that these high activities were not stable under constant potential cycling. By comparison, at higher catalyst loadings, similar to what is applied in fuel cells, the activity became both stable upon potential cycling as well as independent of the catalyst loading, see Figure S6. Therefore, in the following only measurements obtained at catalyst loadings similar to real fuel cells are discussed. Furthermore, before the activity measurements, the electrocatalysts were activated in Ar atmosphere by cyclic voltammetry until a stable curve shape was obtained and a $\mathrm{CO}$-stripping measurement was performed. For Pd catalysts, different results were obtained, depending on whether a CO stripping voltammogram has been recorded before the electro-oxidation or not. Only after a CO stripping voltammogram was recorded, as in the cases discussed below, the catalyst was fully activated. In Figure S7 in the supporting information the formic acid oxidation on an as prepared $\mathrm{Pd} / \mathrm{C}$ sample without prior CO stripping is shown. This phenomenon has not been investigated further, but might be related to hydride formation on $\mathrm{Pd}$ [39]. 

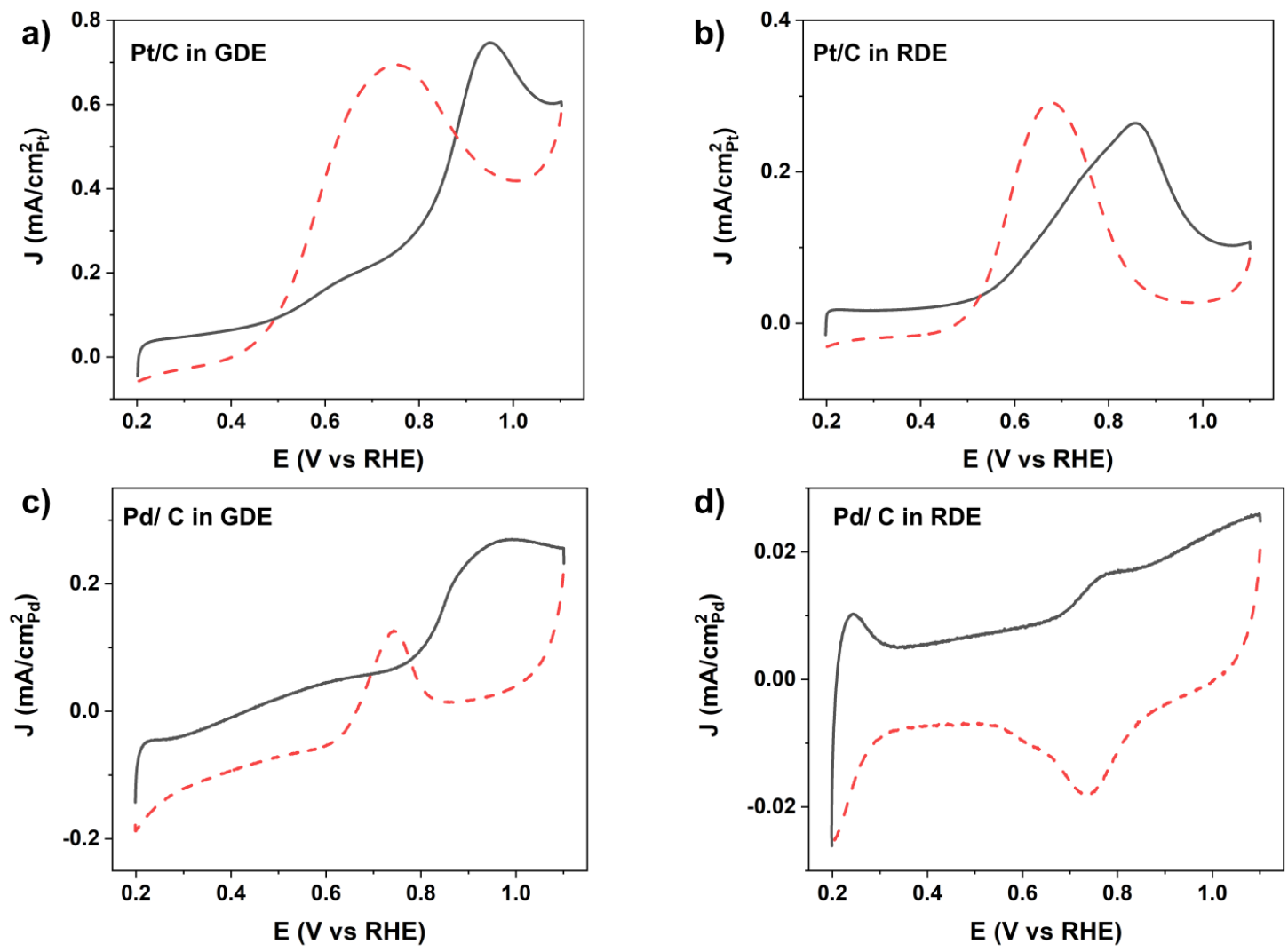

Figure 4. CVs recorded for Pt/C in the presence of methanol in (a) a GDE setup and in (b) a RDE setup. $C V$ s recorded for Pd/C in the presence of methanol in (c) a GDE setup and in (d) a RDE setup. The black lines are the forward going scans, whereas the red dashed lines are the backward going scans. In the GDE setup the methanol was supplied by bubbling Ar gas through a $5.0 \mathrm{M}$ methanol aqueous solution. In the RDE setup the electrolyte was $1.0 \mathrm{M} \mathrm{HClO}_{4}$ aqueous solution containing $0.5 \mathrm{M}$ methanol. The CVs were recorded at a scan rate of $50 \mathrm{mV} \mathrm{s} \mathrm{s}^{-1}$ at room temperature and display the $2^{\text {nd }}$ scan.

In Figure 4, the results from the electro-oxidation of methanol on commercial $\mathrm{Pt} / \mathrm{C}$ and $\mathrm{Pd} / \mathrm{C}$ recorded in GDE and RDE are summarized. For Pt/C similar trends are observed on the thicker catalyst films in the GDE and the very thin catalyst films in the RDE. Most prominent, in both systems a clear hysteresis is seen between the peak potential in the positive and negative going scan. The hysteresis of the peak potential of the main oxidation peak, the maximum current density as well as the peak position (potential) where this is achieved are the main characteristics for an evaluation of the electro-oxidation of methanol. The hysteresis in the oxidation of small organic molecules is related to the "oxidation hysteresis" seen in the CVs recorded in inert atmosphere (Figure 3). The hysteresis indicates surface blocking processes 
that are dependent on the pre-history of the surface. For the small organic molecules it is typically interpreted by the formation of a $\mathrm{CO}$ poisoning species at the surface, i.e., coming from low potentials the catalyst surface is in its reduced form and $\mathrm{CO}_{\mathrm{ad}}$ accumulates during the scan inhibiting the methanol oxidation [5]. By comparison, when scanning in negative direction the catalyst surface is initially oxidized and becomes active upon the reduction of oxide species blocking the surface [40]. Alternatively, a shift in the rate-determining step of the methanol oxidation from methanol dehydration to $\mathrm{OH}$ adsorption by water dissociation has been proposed [41]. Besides, these similarities also differences are observed. In the positive going scan in the GDE setup a pre-peak is seen, which starts around $0.5 \mathrm{~V}_{\mathrm{RHE}}$. Also the deactivation due to Pt oxide formation is less pronounced than in the RDE. Last but not least, despite the thicker catalyst layer the surface normalized current densities at the peak potential are more than two times higher than in the RDE, i.e., $0.75 \pm 0.03$ vs. $0.26 \pm 0.02 \mathrm{~mA} \mathrm{~cm}^{-2} \mathrm{Pt}$, see also Table 1.

Table 1. Summary of the results of particle size, surface area, catalyst loading, ECSA, and formic acid and methanol oxidation activities.

\begin{tabular}{|c|c|c|c|c|c|c|c|c|c|c|c|c|c|}
\hline \multirow{3}{*}{ catalyst } & \multirow{3}{*}{$\begin{array}{c}\text { Particle } \\
\text { size by } \\
\text { TEM } \\
\text { nm }\end{array}$} & \multicolumn{2}{|c|}{ GDE } & \multicolumn{2}{|c|}{ RDE } & \multicolumn{4}{|c|}{ Formic acid oxidation } & \multicolumn{4}{|c|}{ Methanol Oxidation } \\
\hline & & \multirow{2}{*}{$\begin{array}{l}\text { Loading } \\
\mu \mathrm{g} \mathrm{cm}^{-2}\end{array}$} & \multirow{2}{*}{$\begin{array}{l}\text { ECSA } \\
\mathrm{m}^{2} \mathrm{~g}^{-1}\end{array}$} & \multirow{2}{*}{$\begin{array}{l}\text { Loading } \\
\mu \mathrm{g} \mathrm{cm}^{-2}\end{array}$} & \multirow{2}{*}{$\begin{array}{l}\text { ECSA } \\
\mathrm{m}^{2} \mathrm{~g}^{-1}\end{array}$} & & & \multicolumn{2}{|c|}{$\mathrm{RDE}$} & \multicolumn{2}{|c|}{ GDE } & \multicolumn{2}{|c|}{ RDE } \\
\hline & & & & & & \multicolumn{4}{|c|}{$\mathrm{V}^{\mathrm{a}}: \mathrm{mA} \mathrm{cm}^{-2}{ }_{\text {metal }}^{\mathrm{b}}$} & \multicolumn{4}{|c|}{$\mathrm{V}^{\mathrm{a}}: \mathrm{mA} \mathrm{cm}^{-2}$ metal $^{\mathrm{b}}$} \\
\hline $\mathrm{Pd} / \mathrm{C}$ & $\begin{array}{c}4.2 \\
\pm 0.9\end{array}$ & 141 & $\begin{array}{r}123 \\
\pm 11\end{array}$ & 8.0 & $\begin{array}{r}149 \\
\pm 15\end{array}$ & $\begin{array}{c}0.30 \\
- \\
0.34\end{array}$ & $\begin{array}{c}0.97 \\
\pm \\
0.07\end{array}$ & $\begin{array}{c}0.42 \\
- \\
0.44\end{array}$ & $\begin{array}{c}0.94 \\
\pm 0.06\end{array}$ & $\begin{array}{c}0.87 \\
- \\
0.88^{\mathrm{c}}\end{array}$ & $\begin{array}{c}29.0 \\
\pm 0.9^{\mathrm{c}}\end{array}$ & $\begin{array}{c}0.83 \\
- \\
0.84^{\mathrm{c}}\end{array}$ & $\begin{aligned} & 1.1 \\
\pm & 0.07^{\mathrm{c}}\end{aligned}$ \\
\hline $\mathbf{P t} / \mathrm{C}$ & $\begin{array}{c}1.6 \\
\pm 0.4\end{array}$ & 143 & $\begin{array}{l}124 \\
\pm 5\end{array}$ & 7.5 & $\begin{array}{l}181 \\
\pm 9\end{array}$ & $\begin{array}{c}0.50 \\
- \\
0.51\end{array}$ & $\begin{array}{c}0.26 \\
\pm \\
0.04\end{array}$ & $\begin{array}{c}0.55 \\
- \\
0.56\end{array}$ & $\begin{array}{c}0.14 \\
\pm 0.03\end{array}$ & $\begin{array}{c}0.94 \\
- \\
0.95\end{array}$ & $\begin{array}{c}0.75 \\
\pm 0.03\end{array}$ & 0.86 & $\begin{array}{c}0.26 \\
\pm 0.02\end{array}$ \\
\hline
\end{tabular}

${ }^{a}$ Peak potential; ${ }^{\mathrm{b}}$ current density at peak potential; ${ }^{\mathrm{c}}$ measured in alkaline conditions, see Figure 5 . The error bars in ECSA and currents indicate the standard deviation from three measurements. The determination of peak potentials is given as range.

This observation might be related to the different methanol concentrations at the catalyst surface. However, at the chosen conditions no mass transport limitations are observed in the RDE setup. Therefore, it seems that in the GDE setup the same catalyst can provide higher 
specific activities than in an aqueous electrolyte despite the thicker catalyst layer. This might be further evidence of a lack of activity inhibition (as in the CO stripping voltammetry) due to (the lack of) specific anion adsorption in the GDE setup.

Switching to $\mathrm{Pd} / \mathrm{C}$ instead of $\mathrm{Pt} / \mathrm{C}$, in the $\mathrm{RDE} \mathrm{Pd} / \mathrm{C}$ is completely inactive for the methanol oxidation reaction and basically the same $\mathrm{CV}$ is recorded with and without the presence of methanol in the supporting electrolyte. The inactivity of Pd for the methanol oxidation is well established in aqueous acidic electrolyte and in contrast to alkaline electrolyte [42]. Although in the GDE setup minor oxidation currents on $\mathrm{Pd} / \mathrm{C}$ are recorded, the reached current density high enough to be technologically relevant. In the GDE setup, the acidic Nafion membrane can be easily exchanged by an alkaline anion exchange membrane [43]. In Figure 5, it is demonstrated that in alkaline environment indeed $\mathrm{Pd} / \mathrm{C}$ is active for the methanol oxidation reaction. The features in both setups, i.e., GDE and RDE are similar, however, the differences in specific activity between the two setups are even more significant. Roughly 25 times higher specific current densities are observed. In addition, in the negative going scan the re-activation of the Pd due to the reduction of the oxide is sharper and more pronounced.
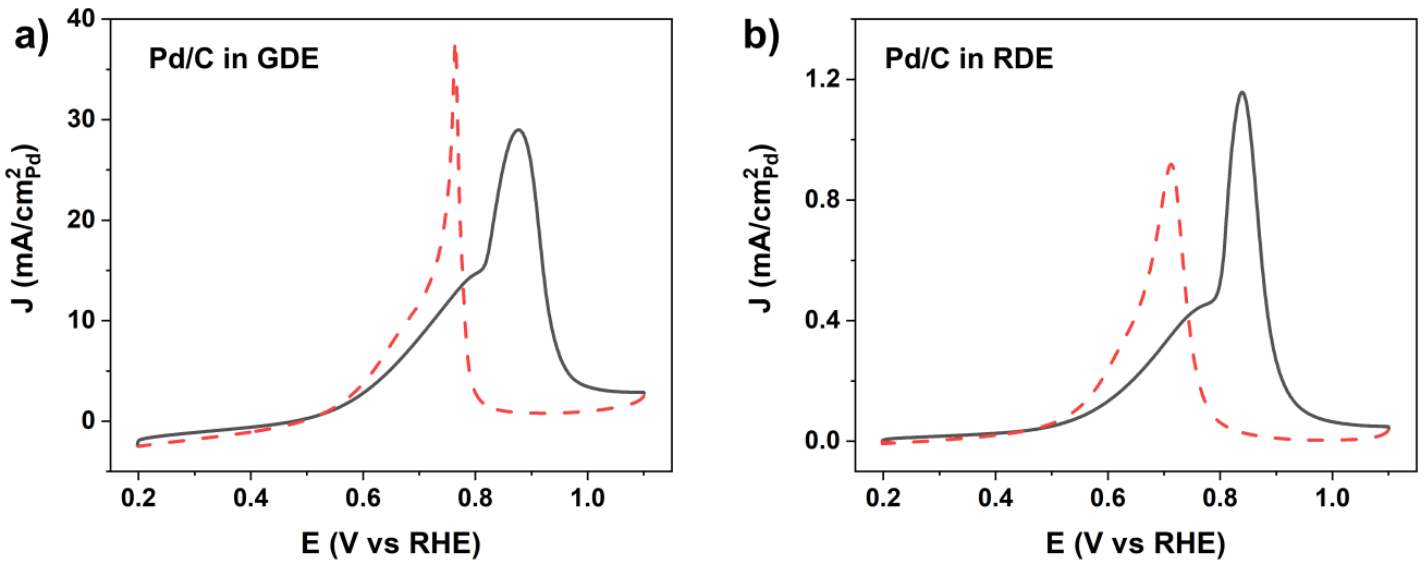

Figure 5. CVs recorded for Pd/C in the presence of methanol in a GDE setup containing (a) an alkaline anion exchange membrane and (b) in a RDE setup with $1.0 \mathrm{M}$ aqueous $\mathrm{KOH}$ containing $0.5 \mathrm{M}$ methanol. The black lines are the forward going scans, whereas the red dashed lines are the negative going scans. In the GDE setup the methanol was supplied by bubbling Ar gas through a 5.0 M methanol 
aqueous solution. The CVs were recorded at a scan rate of $50 \mathrm{mV} \mathrm{s}^{-1}$ at room temperature and display the $2^{\text {nd }}$ scan.

In addition to methanol, we also studied the electro-oxidation of formic acid on $\mathrm{Pt} / \mathrm{C}$ and $\mathrm{Pd} / \mathrm{C}$ in the two setups. The results are summarized in Figure 6. For the electro-oxidation of formic acid, the peak position (potential) of the main oxidation peak, its current density as well as the observed hysteresis between forward and backward going scan are also the main characteristics for an evaluation of the performance. The RDE measurements confirm that $\mathrm{Pd} / \mathrm{C}$ is active for formic acid electro-oxidation in acidic environment, while $\mathrm{Pt} / \mathrm{C}$ is inactive [42]. That is, formic acid oxidation on $\mathrm{Pt} / \mathrm{C}$ is strongly inhibited and a large hysteresis is seen in the $\mathrm{RDE}$ measurements. By comparison, in the GDE the formic acid oxidation on Pt/C exhibits a lower hysteresis, however, the observed current densities are rather low.

In contrast to $\mathrm{Pt} / \mathrm{C}, \mathrm{Pd} / \mathrm{C}$ exhibits a low peak potential, high current densities, and little hysteresis. It is seen that the performance based on peak position in the positive going scan direction is significantly improved in GDE setup as compared to the RDE, i.e., a peak position of 0.34 vs. $0.44 \mathrm{~V}_{\mathrm{RHE}}$ is recorded, see Table 1. This shift in peak potential of the main oxidation peak by $\sim 100 \mathrm{mV}$ to lower potentials in the GDE setup can be associated with a reduced overpotential. At the same time peak current density is roughly the same, i.e., $0.97 \pm 0.07 \mathrm{vs}$ $0.94 \pm 0.06 \mathrm{~mA} \mathrm{~cm}^{-2} \mathrm{Pd}$. Again, this difference between GDE and RDE might be correlated to specific anion adsorption. The onset of formic acid oxidation is associated with the desorption of $\mathrm{H}_{\text {upd. }}$ In an aqueous acid electrolyte there will be always an interplay between $\mathrm{H}_{\text {upd }}$ desorption and anion adsorption while in membrane electrolyte no mobile anions exist. However, in the GDE a clear hysteresis and asymmetric oxidation peaks are seen in the negative going scan. It seems that in the GDE, at higher electrode potentials (> $\left.0.4 \mathrm{~V}_{\mathrm{RHE}}\right)$, the $\mathrm{Pd} / \mathrm{C}$ catalyst becomes inhibited by the formation of surface poisoning species, while this seems not to be the case in the RDE measurements. 

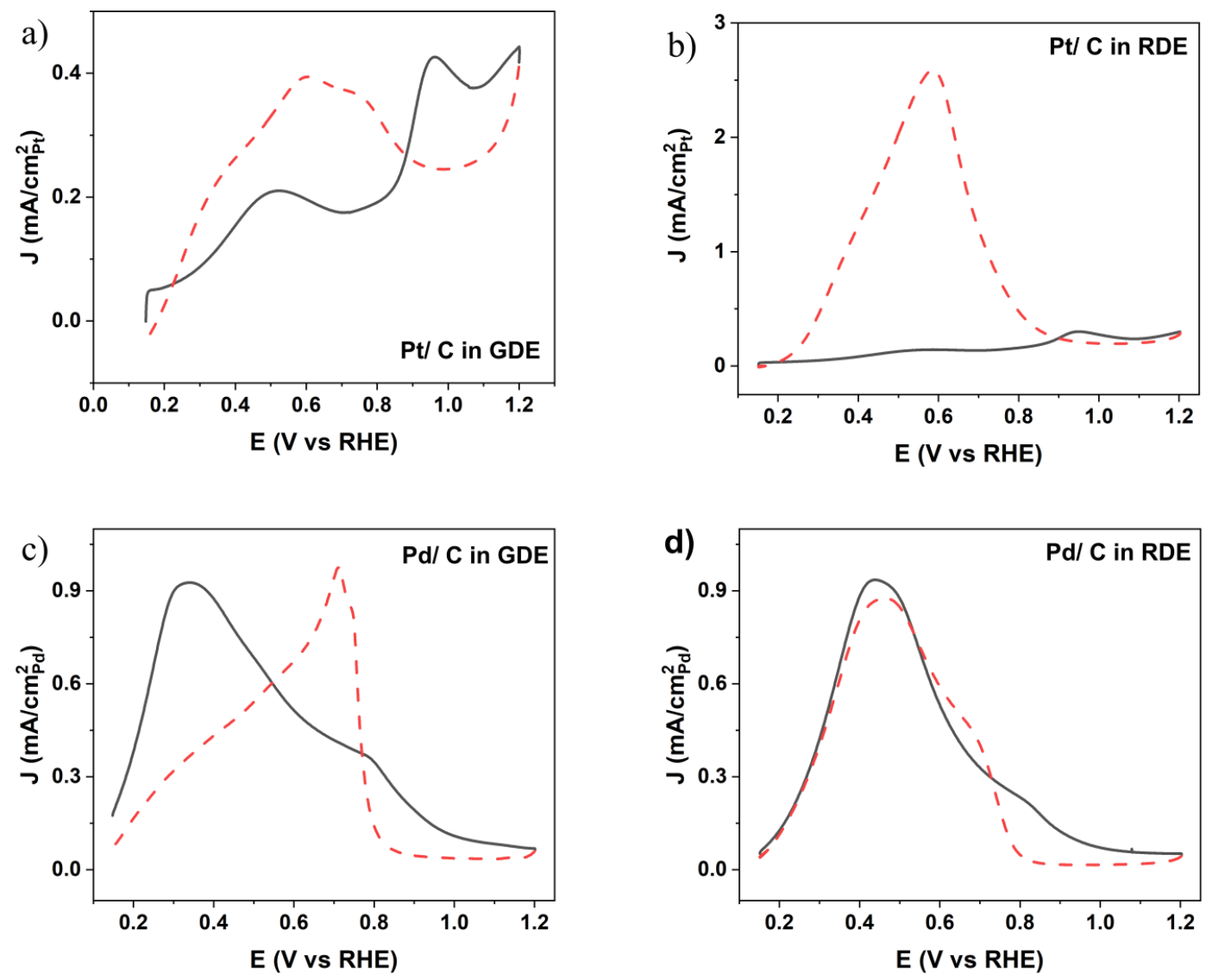

Figure 6. CVs of formic acid oxidation with (a) Pt/C and (c) Pd/C recorded in a GDE setup as well as (b) $P t / C$ and (d) Pd/C measured in a RDE setup. The black lines are the forward going scans, whereas the red dashed lines are the negative going scans. All curves were recorded at room temperature with a scan rate of $50 \mathrm{mV} \mathrm{s}^{-1}$ and display the $2^{\text {nd }}$ scan. In the GDE, Ar was bubbled through 5.0 M formic acid aqueous solution. The electrolyte in the RDE was $1.0 \mathrm{M} \mathrm{HClO}_{4}+0.5 \mathrm{M}$ formic acid.

\section{Conclusion}

In the presented work, the application of a GDE setup for the electro-oxidation of volatile small organic molecules is presented. Both methanol and formic acid are potential fuels for fuel cells, i.e., so-called direct methanol/formic acid fuel cells. It is shown that the GDE setup that has been previously used for the investigation of oxygen reduction reaction catalysts at LT-PEMFC conditions, can be easily adopted for the study of these reactants. The reactant is simply introduced via the humidification of the gas stream. In contrast to the conventional RDE technique, catalyst films with realistic thicknesses for applications are studied in the GDE setup. Furthermore, the catalyst is not in direct contact to a liquid electrolyte, but a catalyst - 
membrane electrolyte interface is formed. Comparing the electrochemical responses in the two systems in a qualitative fashion, similar electrochemical behavior is observed in the RDE and GDE. Nevertheless, differences in specific activity and the peak potential of the main oxidation peak, and the hysteresis between positive and negative going scan be observed, which might be important for an extrapolation of the results from a catalyst screening to their use in direct methanol or direct formic acid fuel cells. The GDE approach therefore provides an important addition to the RDE approach in order to bridge the gap to MEA testing. The data provided can be used as a benchmark for future studies.

\section{Acknowledgements}

This work was supported by the Swiss National Science Foundation (SNSF) via the project No. 200021_184742. Damin Zhang and Jia Du acknowledge funding from the China Scholarship Council (CSC). Jonathan Quinson acknowledges the European Union's Horizon 2020 research and innovation program under the Marie Skłodowska-Curie grant agreement No. 840523 (CoSolCat). S. B. Simonsen and L. Theil Kuhn, Technical University of Denmark, are thanked for access to TEM. The Niels Bohr Institute, University of Copenhagen, for access to SAXS equipment and in particular J. J. K. Kirkensgaard. Gustav K.H. Wiberg, University of Bern, is acknowledged for the sketch in Figure 1.

\section{References}

[1] A. Kongkanand, M.F. Mathias, The Priority and Challenge of High-Power Performance of Low-Platinum Proton-Exchange Membrane Fuel Cells, J. Phys. Chem. Lett. 7 (2016) 1127-1137. https://doi.org/10.1021/acs.jpclett.6b00216.

[2] T. Yoshida, K. Kojima, Toyota MIRAI Fuel Cell Vehicle and Progress Toward a Future Hydrogen Society, Electrochem. Soc. Interface. $24 \quad$ (2015) 45-49. https://doi.org/10.1149/2.F03152if. 
[3] X. Yu, P.G. Pickup, Recent advances in direct formic acid fuel cells (DFAFC), J. Power Sources. 182 (2008) 124-132. https://doi.org/10.1016/j.jpowsour.2008.03.075.

[4] L. Carrette, K.A. Friedrich, U. Stimming, Fuel Cells - Fundamentals and Applications, Fuel Cells. 1 (2001) 5-39.

[5] R. Parsons, T. Vandernoot, The oxidation of small organic molecules A survey of recent fuel cell related research, J. Electroanal. Chem. 257 (1988) 9-45.

[6] N.M. Markovíc, P.N. Ross, Surface science studies of model fuel cell electrocatalysts, Surf. Sci. Rep. 45 (2002) 117-229. https://doi.org/10.1016/s0167-5729(01)00022-x.

[7] T. Yajima, H. Uchida, M. Watanabe, In-situ ATR-FTIR spectroscopic study of electrooxidation of methanol and adsorbed CO at Pt-Ru alloy, J. Phys. Chem. B. 108 (2004) 2654-2659. https://doi.org/10.1021/jp037215q.

[8] M. Arenz, V. Stamenkovic, T.J. Schmidt, K. Wandelt, P.N. Ross, N.M. Markovic, The electro-oxidation of formic acid on Pt-Pd single crystal bimetallic surfaces, Phys. Chem. Chem. Phys. 5 (2003). https://doi.org/10.1039/b306307k.

[9] M. Arenz, V. Stamenkovic, P.N. Ross, N.M. Markovic, Surface (electro-)chemistry on Pt(111) modified by a Pseudomorphic Pd monolayer, Surf. Sci. 573 (2004). https://doi.org/10.1016/j.susc.2004.05.144.

[10] M. Inaba, J. Quinson, J.R. Bucher, M. Arenz, On the preparation and testing of fuel cell catalysts using the thin film rotating disk electrode method, J. Vis. Exp. 2018 (2018). https://doi.org/10.3791/57105.

[11] B. Han, C.E. Carlton, A. Kongkanand, R.S. Kukreja, B.R. Theobald, L. Gan, R. O’Malley, P. Strasser, F.T. Wagner, Y. Shao-Horn, Record activity and stability of dealloyed bimetallic catalysts for proton exchange membrane fuel cells, Energy Environ. Sci. 8 (2015) 258-266. https://doi.org/10.1039/c4ee02144d.

[12] A.R. Kucernak, E. Toyoda, Studying the oxygen reduction and hydrogen oxidation reactions under realistic fuel cell conditions, Electrochem. Commun. (2008). https://doi.org/10.1016/j.elecom.2008.09.001.

[13] C.M. Zalitis, D. Kramer, A.R. Kucernak, Electrocatalytic performance of fuel cell 
reactions at low catalyst loading and high mass transport, Phys. Chem. Chem. Phys. (2013). https://doi.org/10.1039/c3cp44431g.

[14] G.K.H. Wiberg, M. Fleige, M. Arenz, Gas diffusion electrode setup for catalyst testing in concentrated phosphoric acid at elevated temperatures, Rev. Sci. Instrum. 86 (2015). https://doi.org/10.1063/1.4908169.

[15] B.A. Pinaud, A. Bonakdarpour, L. Daniel, J. Sharman, D.P. Wilkinson, Key Considerations for High Current Fuel Cell Catalyst Testing in an Electrochemical HalfCell, J. Electrochem. Soc. (2017). https://doi.org/10.1149/2.0891704jes.

[16] K. Ehelebe, J. Knöppel, M. Bierling, B. Mayerhöfer, T. Böhm, N. Kulyk, S. Thiele, K. Mayrhofer, S. Cherevko, Platinum Dissolution in Realistic Fuel Cell Catalyst Layers, Angew. Chemie Int. Ed. (2021). https://doi.org/10.1002/anie.202014711.

[17] K. Ehelebe, D. Seeberger, M.T.Y. Paul, S. Thiele, K.J.J. Mayrhofer, S. Cherevko, Evaluating Electrocatalysts at Relevant Currents in a Half-Cell: The Impact of Pt Loading on Oxygen Reduction Reaction, J. Electrochem. Soc. 166 (2019) F1259F1268. https://doi.org/10.1149/2.0911915jes.

[18] M. Inaba, A.W. Jensen, G.W. Sievers, M. Escudero-Escribano, A. Zana, M. Arenz, Benchmarking high surface area electrocatalysts in a gas diffusion electrode: measurement of oxygen reduction activities under realistic conditions, Energy Environ. Sci. 11 (2018) 988-994. https://doi.org/10.1039/C8EE00019K.

[19] S. Alinejad, J. Quinson, J. Schroeder, J. Kirkensgaard, M. Arenz, Carbon-Supported Platinum Electrocatalysts Probed in a Gas Diffusion Setup with Alkaline Environment: How Particle Size and Mesoscopic Environment Influence the Degradation Mechanism, ACS Catal. 10 (n.d.) 13040-13049. https://doi.org/10.1021/acscatal.0c03184.

[20] S. Alinejad, M. Inaba, J. Schröder, J. Du, J. Quinson, A. Zana, M. Arenz, Testing fuel cell catalysts under more realistic reaction conditions: accelerated stress tests in a gas diffusion electrode setup, J. Phys. Energy. 2 (2020) 024003. https://doi.org/10.1088/2515-7655/ab67e2.

[21] J. Schröder, J. Quinson, J.K. Mathiesen, J.J.K. Kirkensgaard, S. Alinejad, V.A. Mints, K.M.Ø. Jensen, M. Arenz, A New Approach to Probe the Degradation of Fuel Cell 
Catalysts under Realistic Conditions: Combining Tests in a Gas Diffusion Electrode Setup with Small Angle X-ray Scattering, J. Electrochem. Soc. (2020). https://doi.org/10.1149/1945-7111/abbdd2.

[22] L. Pan, S. Ott, F. Dionigi, P. Strasser, Current challenges related to the deployment of shape-controlled Pt alloy oxygen reduction reaction nanocatalysts into low Pt-loaded cathode layers of proton exchange membrane fuel cells, Curr. Opin. Electrochem. 18 (2019) 61-71. https://doi.org/10.1016/j.coelec.2019.10.011.

[23] J. Schröder, V.A. Mints, A. Bornet, E. Berner, M. Fathi Tovini, J. Quinson, G.K.H. Wiberg, F. Bizzotto, H.A. El-Sayed, M. Arenz, The Gas Diffusion Electrode Setup as Straightforward Testing Device for Proton Exchange Membrane Water Electrolyzer Catalysts, JACS Au. 1 (2021) 247-251. https://doi.org/10.1021/jacsau.1c00015.

[24] F.R. Nikkuni, B. Vion-Dury, L. Dubau, F. Maillard, E.A. Ticianelli, M. Chatenet, The role of water in the degradation of $\mathrm{Pt} 3 \mathrm{Co} / \mathrm{C}$ nanoparticles: An Identical Location Transmission Electron Microscopy study in polymer electrolyte environment, Appl. Catal. B Environ. 156-157 301-306. https://doi.org/10.1016/j.apcatb.2014.03.029.

[25] K. Kodama, A. Shinohara, N. Hasegawa, K. Shinozaki, R. Jinnouchi, T. Suzuki, T. Hatanaka, Y. Morimoto, Catalyst Poisoning Property of Sulfonimide Acid Ionomer on $\begin{array}{lllllll}\text { Pt (111) Surface, J. Electrochem. Soc. } 161 & \text { (2014) F649-F652. }\end{array}$ https://doi.org/10.1149/2.051405jes.

[26] K. Shinozaki, Y. Morimoto, B.S. Pivovar, S.S. Kocha, Re-examination of the Pt Particle Size Effect on the Oxygen Reduction Reaction for Ultrathin Uniform Pt/C Catalyst Layers without Influence from Nafion, Electrochim. Acta. 213 (2016) 783-790. https://doi.org/10.1016/j.electacta.2016.08.001.

[27] D. Strmcnik, K. Kodama, D. Van Der Vliet, J. Greeley, V.R. Stamenkovic, N.M. Marković, The role of non-covalent interactions in electrocatalytic fuel-cell reactions on platinum, Nat. Chem. 1 (2009) 466-472. https://doi.org/10.1038/nchem.330.

[28] G.K.H. Wiberg, The development of a state-of-the-art experimental setup demonstrated by the investigation of fuel cell reactions in alkaline electrolyte., Technical University 
Munich, Germany, 2010. http://nbn-resolving.de/urn/resolver.pl?urn:nbn:de:bvb:91diss-20101008-993285-1-2.

[29] M. Inaba, J. Quinson, J.R. Bucher, M. Arenz, On the Preparation and Testing of Fuel Cell Catalysts Using the Thin Film Rotating Disk Electrode Method, J. Vis. Exp. 133 (2018) e57105. https://doi.org/10.3791/57105.

[30] S. Rudi, C. Cui, L. Gan, P. Strasser, Comparative Study of the Electrocatalytically Active Surface Areas (ECSAs) of Pt Alloy Nanoparticles Evaluated by Hupd and COstripping voltammetry, $\quad$ Electrocatalysis. $\quad 5 \quad$ (2014) 408-418. https://doi.org/10.1007/s12678-014-0205-2.

[31] T. Chierchie, C. Mayer, W.J. Lorenz, Structural changes of surface oxide layers on palladium, J. Electroanal. Chem. Interfacial Electrochem. 135 (1982) 211-220. https://doi.org/10.1016/0368-1874(82)85121-6.

[32] M. Inaba, A.W. Jensen, G.W. Sievers, M. Escudero-Escribano, A. Zana, M. Arenz, Benchmarking high surface area electrocatalysts in a gas diffusion electrode: Measurement of oxygen reduction activities under realistic conditions, Energy Environ. Sci. 11 (2018). https://doi.org/10.1039/c8ee00019k.

[33] V. Yarlagadda, S.E. McKinney, C.L. Keary, L. Thompson, B. Zulevi, A. Kongkanand, Preparation of PEMFC Electrodes from Milligram-Amounts of Catalyst Powder, J. Electrochem. Soc. 164 (2017) F845-F849. https://doi.org/10.1149/2.1461707jes.

[34] G.K.H. Wiberg, M. Fleige, M. Arenz, Gas diffusion electrode setup for catalyst testing in concentrated phosphoric acid at elevated temperatures, Rev. Sci. Instrum. 86 (2015). https://doi.org/10.1063/1.4908169.

[35] T. Solomun, Electro-oxidation of the Pd (100) surface, J. Electroanal. Chem. Interfacial Electrochem. 255 (1988) 163-177. https://doi.org/10.1016/0022-0728(88)80012-3.

[36] M. Inaba, J. Quinson, M. Arenz, pH matters: The influence of the catalyst ink on the oxygen reduction activity determined in thin film rotating disk electrode measurements, J. Power Sources. 353 (2017) 19-27. https://doi.org/10.1016/j.jpowsour.2017.03.140.

[37] A.J. Bard, L.R. Faulkner, Electrochemical Methods: Fundamentals and Applications, 
2nd Editio, Wiley-VCH Verlag, n.d.

[38] X. Wang, W. Wang, Z. Qi, C. Zhao, H. Ji, Z. Zhang, Electrochemical catalytic activities of nanoporous palladium rods for methanol electro-oxidation, J. Power Sources. 195 (2010) 6740-6747. https://doi.org/10.1016/J.JPOWSOUR.2010.03.098.

[39] A. Kongkanand, N.P. Subramanian, Y. Yu, Z. Liu, H. Igarashi, D.A. Muller, Achieving High-Power PEM Fuel Cell Performance with an Ultralow-Pt-Content Core-Shell Catalyst, ACS Catal. 6 (2016) 1578-1583. https://doi.org/10.1021/acscatal.5b02819.

[40] M. Baldauf, D.M. Kolb, Formic acid oxidation on ultrathin Pd films on Au(hkl) and Pt(hkl) electrodes, J. Phys. Chem. $100 \quad$ (1996) 11375-11381. https://doi.org/10.1021/jp952859m.

[41] D.Y. Chung, K.-J. Lee, Y.-E. Sung, Methanol Electro-Oxidation on the Pt Surface: Revisiting the Cyclic Voltammetry Interpretation, J. Phys. Chem. C. 120 (2016) 90289035. https://doi.org/10.1021/ACS.JPCC.5B12303.

[42] C. Koenigsmann, S.S. Wong, Tailoring chemical composition to achieve enhanced methanol oxidation reaction and methanol-tolerant oxygen reduction reaction performance in palladium-based nanowire systems, ACS Catal. 3 (2013) 2031-2040. https://doi.org/10.1021/cs400380t.

[43] S. Alinejad, J. Quinson, J.J. Schröder, J.J.K. Kirkensgaard, M. Arenz, J. J. K. Kirkensgaard, M. Arenz, J.J.K. Kirkensgaard, M. Arenz, Carbon-Supported Platinum Electrocatalysts Probed in a Gas Diffusion Setup with Alkaline Environment: How Particle Size and Mesoscopic Environment Influence the Degradation Mechanism, ACS Catal. 10 (2020) 13040-13049. https://doi.org/10.1021/acscatal.0c03184. 


\section{Supporting information}

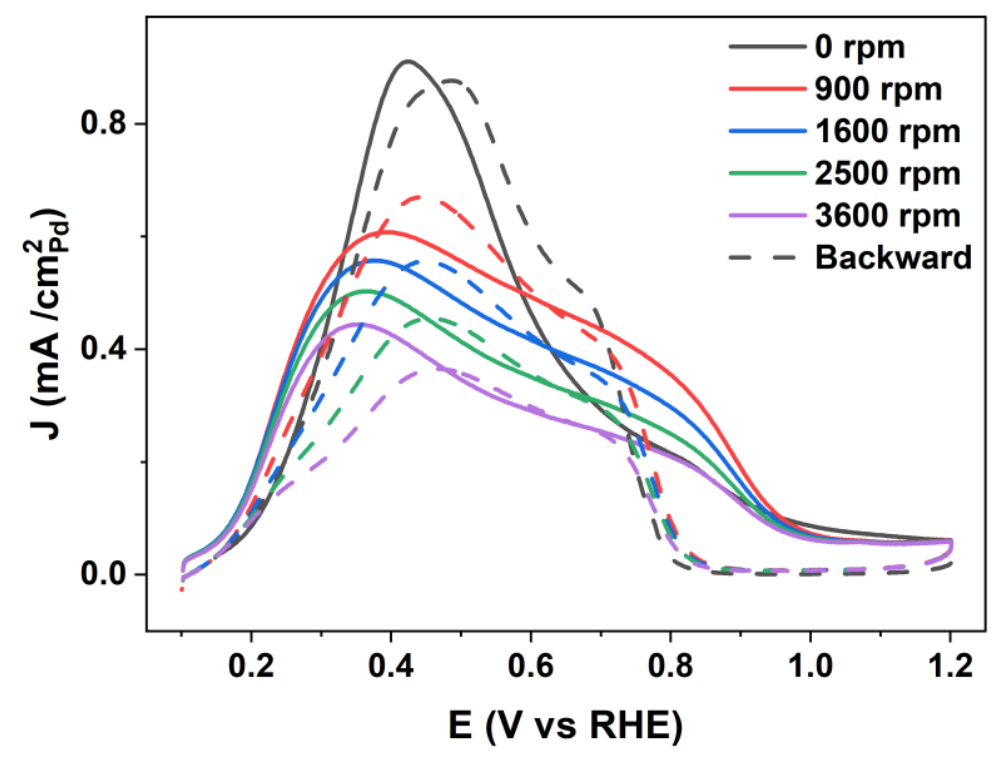

Figure S1. CV of formic acid oxidation with Pd/C measured in a RDE setup at different rotation rates, as indicated. All curves were recorded at room temperature with a scan rate of $50 \mathrm{mV} \mathrm{s} \mathrm{s}^{-1}$. The solid lines indicate the forward going scan, the dashed lines the backward going scans. The electrolyte was 1.0 $\mathrm{M} \mathrm{HClO}_{4}+0.5 \mathrm{M}$ formic acid.

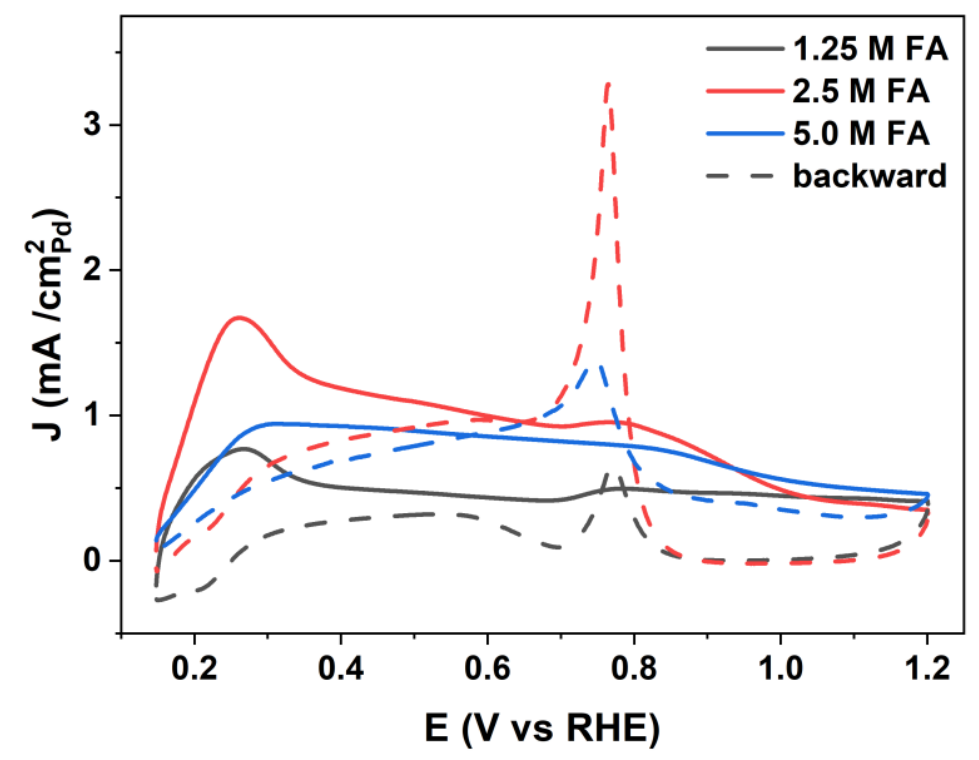

Figure S2. CVs recorded for Pd/C in the presence of formic acid oxidation in a GDE setup. The formic acid was supplied to the catalyst by bubbling Ar through 1, 2.5, and 5.0 M formic acid aqueous solution. The nominal catalyst loadings was $200 \mu \mathrm{g}_{P d} \mathrm{Cm}^{-2}{ }_{\text {geo. }}$. All curves were recorded at room temperature with 
a scan rate of $50 \mathrm{mV} \mathrm{s}^{-1}$ and display the $2^{\text {nd }}$ scan. The solid lines are the forward going scans, and the dashed lines the backward going scans.

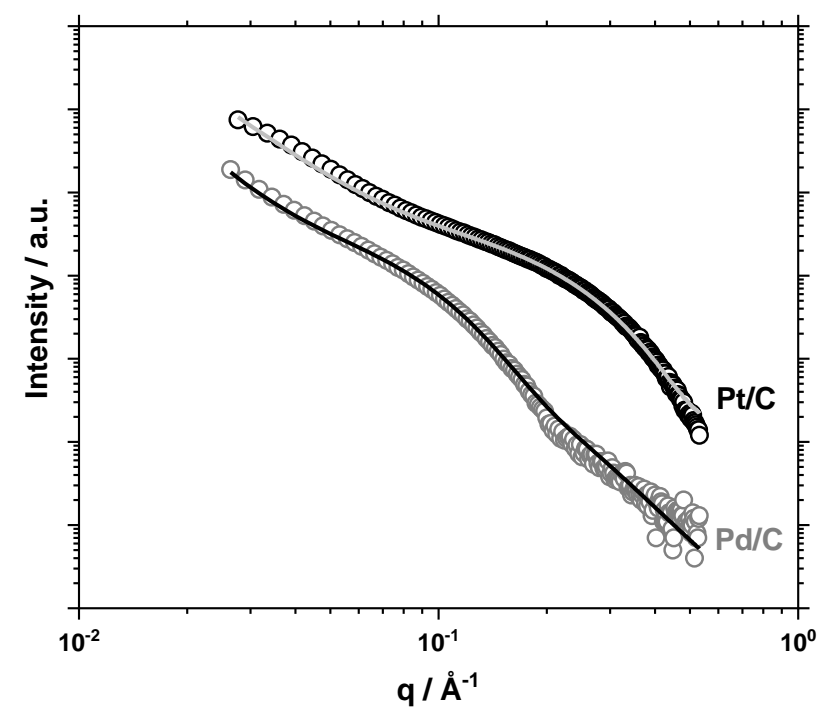

Figure S3. SAXS data (circles) and fits (lines) for the Pt/C and Pd/C samples, as indicated, after background subtraction. The two data set are presented with an offset for the sake of clarity.

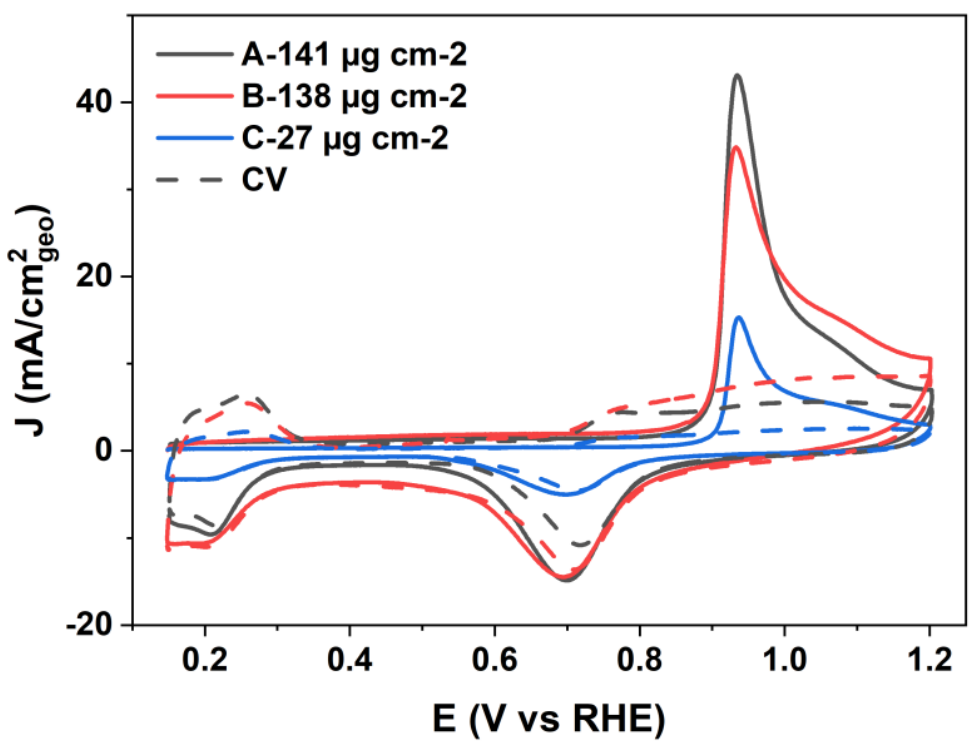

Figure S4. CO stripping voltammograms (solid lines) and corresponding CVs (dashed lines) recorded in GDE setup for Pd/C with different metal loadings as indicated. The CVs and CO stripping voltammograms were recorded with a scan rate of $50 \mathrm{mV} \mathrm{s} \mathrm{s}^{-1}$ under humidified Ar atmosphere at room temperature. The metal loadings were 141, 138 and $27 \mu g_{P d} \mathrm{~cm}^{-2}$ geo. Based on the CO stripping curves ECSA values of 119,124 , and $126 \mathrm{~m}^{2} \mathrm{~g}^{-1} \mathrm{Pd}$, respectively, are determined demonstrating that the accessibility of the catalyst does not decrease with increasing film thickness. 


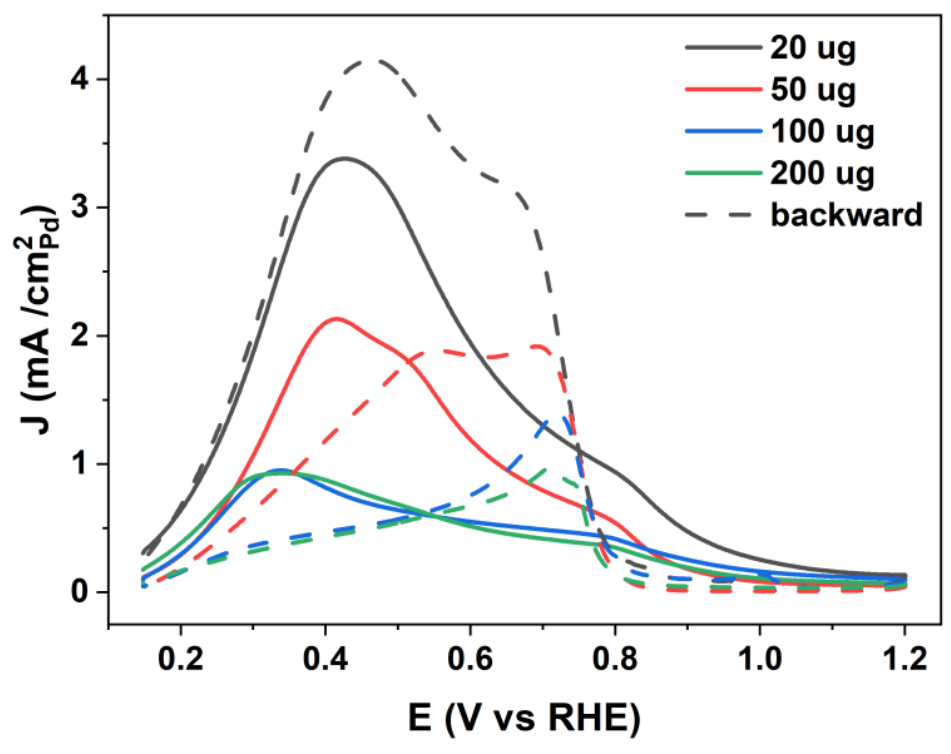

Figure S5. CVs recorded for Pd/C in the presence of formic acid oxidation in a GDE setup. The nominal catalyst loading amount is varied between $20 \mu \mathrm{g}_{P d} \mathrm{~cm}^{-2}{ }_{\text {geo }}, 50 \mu \mathrm{g}_{P d} \mathrm{~cm}_{\mathrm{geo}}^{-2}, 100 \mu \mathrm{g}_{P d} \mathrm{~cm}^{-2}{ }_{\text {geo }}$, and 200 $\mu g_{P d} \mathrm{~cm}^{-2}{ }_{\text {geo. }}$. All curves were recorded at room temperature with a scan rate of $50 \mathrm{mV} \mathrm{s} \mathrm{s}^{-1}$ and display the $2^{\text {nd }}$ scan. The formic acid was supplied to the catalyst by bubbling Ar through 5.0 M formic acid aqueous solution. The solid lines are the forward going scans, and the dashed lines the backward going scans. The measurements demonstrate that the normalized reactivity decreases with the catalyst loading.
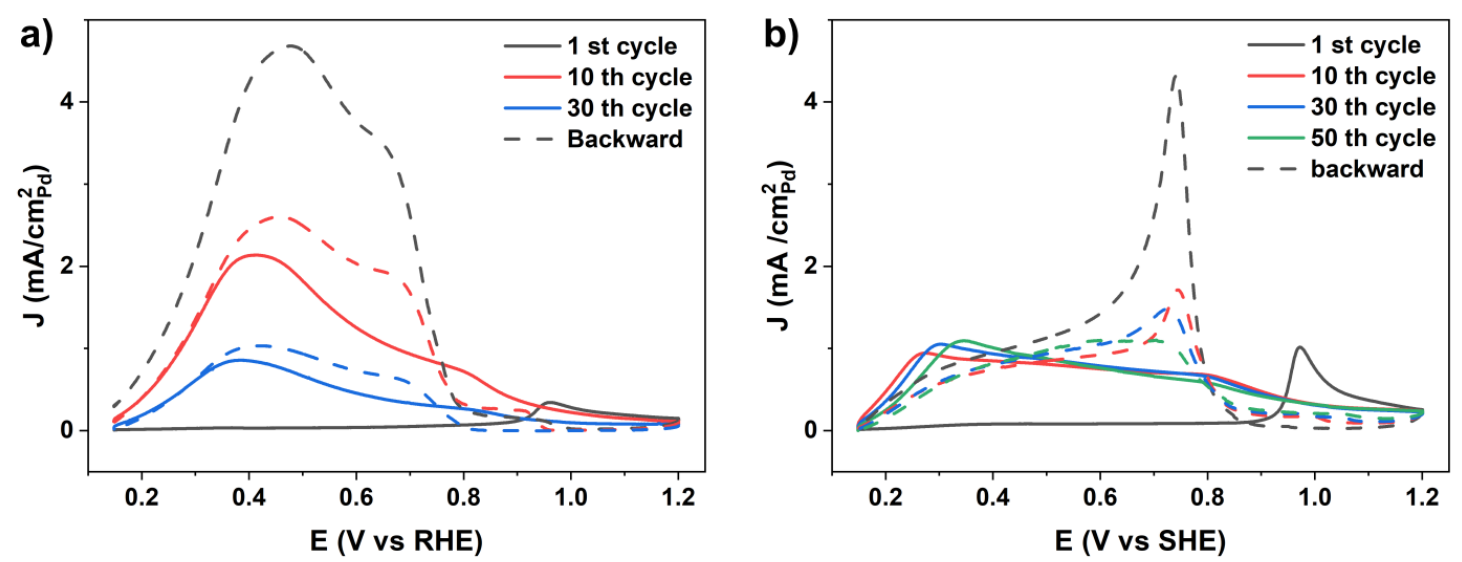

Figure S6. CVs recorded for Pd/C in the presence of formic acid oxidation in a GDE setup. The measurements compare two nominal catalyst loadings, i.e., (a) $20 \mu \mathrm{g}_{P d} \mathrm{~cm}^{-2}{ }_{\text {geo }}$ and (b) $200 \mu \mathrm{g}_{P d} \mathrm{~cm}^{-2}{ }_{\text {geo. }}$. All curves were recorded at room temperature with a scan rate of $50 \mathrm{mV} \mathrm{s}^{-1}$ and display the $1^{\text {st }}, 10^{\text {th }}$, $30^{\text {th }}$ and $50^{\text {th }}$ scan. The formic acid was supplied to the catalyst by bubbling Ar through 5.0 M formic acid aqueous solution. The solid lines are the forward going scans, and the dashed lines the backward going scans. The measurements demonstrate that the normalized reactivity decreases with the catalyst 
loading. It is seen that at lower catalyst loading the current decreases rapidly upon constant cycling, whereas at higher loading, the current was stable upon cycling.

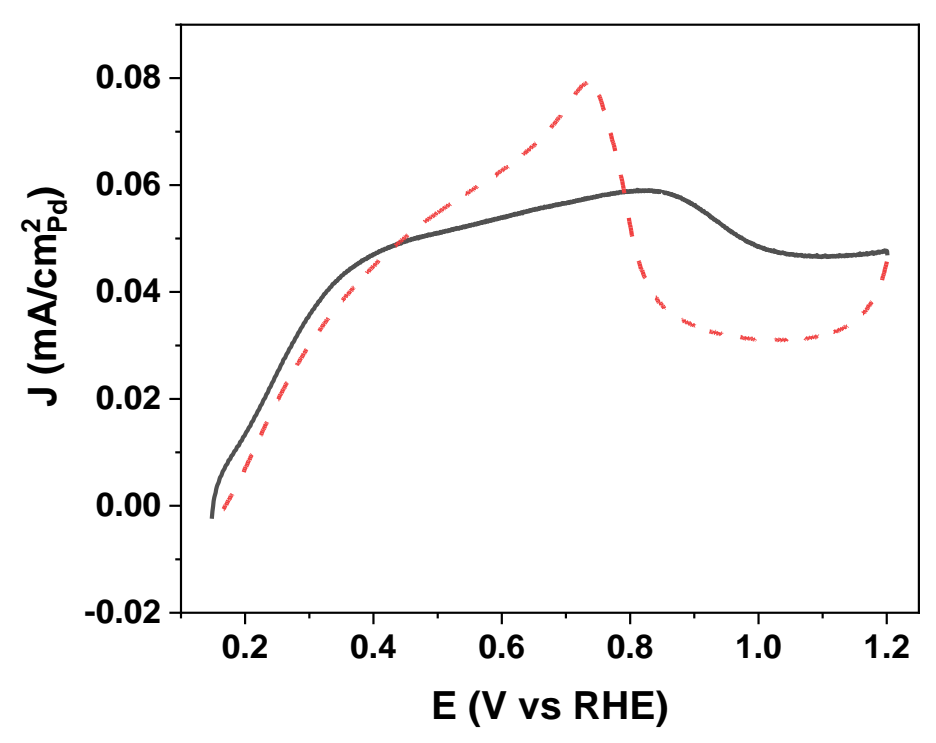

Figure S7. CVs of formic acid oxidation with a pristine Pd/C catalyst (no prior CO stripping voltammogram recorded) measured in a GDE setup at room temperature and a scan rate of $50 \mathrm{mV} \mathrm{s}$. Ar was bubbled 5.0 M formic acid aqueous solution. The upper cell compartment was filled with $1.0 \mathrm{M}$ $\mathrm{HClO}_{4}$. The solid line is the forward going scan and the dashed line the backward going scan. It is seen that the formic acid oxidation with a Pd/C catalyst in its pristine state is significantly inhibited. See also Figure 6. 